\title{
The Evolution Process and Development Approach of the Research on the New Generation of Migrant Workers in China
}

\author{
Peng Liang ${ }^{1, a}$ \\ ${ }^{1}$ Department of management, Zhanjiang University of Science and Technology, Zhanjiang, Guangdong, China \\ ateddybear1299@163.com
}

\begin{abstract}
The new generation of migrant workers is an important part of the "three rural" question in the new era, and it is also a hot and difficult issue that scholars pay attention to. The article uses 2042 core journals and CSSCI research literature as data samples from 2005 to 2021, and uses CiteSpace to conduct a bibliometric analysis on the research topic of "new generation migrant workers". Through the research on the basic situation, research hotspots, frontier evolution, research lines and development trends of the new generation of migrant workers in China, suggestions and prospects for further research in the future are put forward. Looking at the evolution process and main lines of research on the new generation of migrant workers in China in the 21 st century, it has evolved from a simple focus on "employment" to an emphasis on "employment quality", and from a one-way "city integration" to a more focused "Social network", from a relatively superficial "citizenization" to a deeper "identity", from a simple "urbanization" to a people-oriented "new urbanization", and more emphasis on the "village revitalization" of the city to feed back the countryside, etc.. The development of research on the new generation of migrant workers shows that it not only reveals to a certain extent the evolution and cutting-edge trends in the research field of the new generation of migrant workers, but also reflects the development and progress of Chinese society, and reflects the yearning and pursuit of the new generation of migrant workers for a better life in the new era.
\end{abstract}

Keywords: New generation of migrant workers, main research line, evolution process, development approach.

\section{中国新生代农民工研究的演进历程及发展进路}

彭亮 $1, \mathrm{a}$

1 湛江科技学院管理学院, 湛江, 广东, 中国

ateddybear1299@163.com

摘要

新生代农民工是新时代 “三农”工作的重要内容，也是学者们关注的热点和难点问题。文章以 2005-2021 年间 2042 篇核心期刊、CSSCI 研究文献为数据样本, 采用 CiteSpace 对 “新生代农民工” 研究主题进行了文献计量 分析。通过对中国新生代农民工研究的基本情况、研究热点、前沿演进、研究主线及发展趋势等问题进行研究, 提出了今后进一步研究的建议和展望。纵观 21 世纪中国新生代农民工研究的演进历程和研究主线, 从以往的 简单地关注 “就业” 演化为强调 “就业质量”、从单向的 “城市融入” 演变为更加注重人们互动的 “社会网 络”、从相对表面的 “市民化” 演变为更深层次的 “身份认同”、从单纯的 “城镇化” 演变为以人为本的 “新 型城镇化” 和更加强调城市反哺乡村的 “乡村振兴” 等，不仅在一定程度上揭示了新生代农民工研究领域的 演进历程和前沿趋势, 也反映出了中国社会的发展和进步, 反映出了新生代农民工对新时代美好生活的向往与 追求。

关键词: 新生代农民工; 研究主线; 演进历程; 发展进路 


\section{1. 前言}

进入 21 世纪, 我国农民工群体内部出现了代际 更替现象, 新生代农民工逐步登场并引起了社会的广 泛注意。2010 年, 中央一号文件《关于加大统筹城乡 发展力度进一步夯实农业农村发展基础的若干意见》 正式写入“新生代农民工”概念, 党和国家的关注和重 视、新生代农民工群体呈现的新特征和面临的实际问 题, 使得“新生代农民工”议题受到了学术界的广泛关 注, 研究文献迅速增长, 形成了丰硕的研究成果。科 学文献中蕴含着丰富的信息, 但如何从海量文献中科 学快速地找到最为重要的、关键的有效信息却是一个 极大的难题。本文主要采用 Citespace 文献计量分析 软件, 对 21 世纪以来我国新生代农民工研究议题的 研究主线及发展进路进行研究, 以期为今后进一步开 展新生代农民工研究提供有益指导。

\section{2. 数据来源与研究方法}

\section{1 数据来源}

以 CNKI 为数据来源, 在 “高级检索”模式下选取 “核心期刊”、“CSSCI”来源类别, 以“新生代农民工”作 为篇名或关键词进行检索。综合考虑相关文献首现年 份等因素, 出版时间范围选择“2005-2021 年”。经检 索, 得到检索结果共计 2152 篇文献, 采集数据时间 为 2021 年 7 月 12 日。为提高文献的精确性和权威 性, 手工剔除了卷首语、书评、会议通知或综述等非 学术研究性论文, 精炼出 2042 篇样本文献。将文本 数据导入 CiteSpace5.6.R2 软件进行数据转换, 有效记 录为 2042 篇文献, 有效记录比率为 $100 \%$ 。

\section{2 研究方法}

CiteSpace 是美国德雷塞尔大学终身教授陈超美 先生应用 Java 语言开发的一款科学文献数据挖掘及 信息可视化软件。该软件可以通过对作者、研究机构、 研究主题等信息数据的抽取和分析, 挖掘科学文献中 蕴含的潜在知识, 并借助可视化知识图谱直观地呈现 科学知识的结构、规律和分布情况。 ${ }^{\left[{ }_{1}\right]}$ CiteSpace 能 够通过文献计量分析和相关知识聚类、主题词的突发 性探测, 在海量文献中抓住重要信息, 帮助更好地了 解特定研究领域的整体发展状况, 揭示和预测该领域 的研究热点、研究前沿 ${ }^{[2]}$ 。目前, CiteSpace 已经在情 报学、图书管与档案管理、管理科学与工程、教育学、 管理学、社会学等领域普及应用, 是最受国际计量学 研究者公认的技术之一。本文将 CiteSpace 应用于新 生代农民工研究领域的演进历程和发展趋势研究, 主 要从发文作者、研究机构、关键词共现分析、主题词 的突发性探测等方面展开。

\section{3. 我国新生代农民工研究的基本情况}

\section{1 主要研究力量分析}

采用 CiteSpace 进行研究作者的合作网络分析, 选择节点类型(Node Types)=“Author”、时间切片(Time Slicing)=“2005-2021”（每个时间切片为“2 年”), 并将 Selection Criteria 赋值为“Top N=50”, 得到包含 368 个节点 (作者)、133 条连线的作者合作网络图, 网络 密度 (Density) 为 0.002 。根据赖普斯定律计算新生 代农民工研究的核心作者数量, 方法为: $\mathrm{N}=0.749$ *

（Nmax）1/2，其中“N”表示核心作者发文量应达到的 最小数量、“Nmax”表示作者发文量的最大数量。根据 数据显示, $N \max$ 为俞林发表了 24 篇论文。经计算, $\mathrm{N} \approx 4$, 即发文量 4 篇以上的作者为新生代农民工研究 的核心作者（如表 1)。结果表明, 发文量 4 篇以上的 作者人数为 57 人, 发文量共计 364 篇, 约占新生代 农民工研究相关论文总数的 $17.8 \%$, 与稳定的核心作 者群体发文量占比所需达到 $50 \%$ 以上还存在较大差 距, 表明目前新生代农民工研究的核心作者群体尚未 稳定。当然, 这同时也表明新生代农民工研究受到了 学者们的广泛关注。由于作者合作网络密度仅为 0.002 , 表明发文作者之间的合作交流还十分欠缺。

\section{表 1：新生代农民工研究的核心作者及发文量情况} （前 10 位）

\begin{tabular}{|c|c|c|c|c|c|}
\hline $\begin{array}{l}\text { 序 } \\
\text { 号 }\end{array}$ & 作者 & 发文量 & $\begin{array}{l}\text { 序 } \\
\text { 号 }\end{array}$ & 作者 & 发文量 \\
\hline 1 & 俞林 & 24 & 6 & 郑欣 & 11 \\
\hline 2 & 金晓㣌 & 20 & 7 & 沈蕾 & 11 \\
\hline 3 & 李群 & 13 & 8 & 郑爱翔 & 10 \\
\hline 4 & 张宏如 & 12 & 9 & 张广胜 & 9 \\
\hline 5 & 印建兵 & 12 & 10 & 李贵成 & 9 \\
\hline
\end{tabular}

\section{2 主要研究机构分布}

在研究机构分布上, 在发文量前 10 名的研究机 构中（如表 2), 除中国社会科学院（主要为中国社会 科学院社会学研究所、人口与劳动经济研究所) 是科 研院所之外, 其它 9 个研究机构均是高校, 表明高校 是新生代农民工研究的主要力量。其中, 吉林大学发 文量为 44 篇, 排名第一。整体上看, 发文量排名前 10 的研究机构主要集中在我国学术实力雄厚的“双一 流”建设高校, 如吉林大学、南京大学、中国人民大学、 东华大学、南京农业大学、华中师范大学、西北农林 科技大学等。值得注意的是, 无锡职业技术学院是发 文量前 10 位中的唯一一所大专院校, 其凭借在职业 教育等领域专长在新生代农民工研究中表现十分抢 眼, 发文量达到 39 篇。从地域分布来看, 以上研究 机构主要分布在北京、武汉、南京、上海等超大或特 
大城市。此外, 在发文量前 10 位的研究机构中, 南 京大学、无锡职业技术学院、南京农业大学、常州大 学均位于江苏省, 这或许与江苏省同时是吸纳和输出 农民工的大省之一以及其雄厚的高教综合实力等因 素密切相关。

\section{表 2: 新生代农民工研究的主要研究机构情况（前 10 位）}

\begin{tabular}{|c|c|c|c|c|c|c|}
\hline $\begin{array}{c}\text { 序 } \\
\text { 号 }\end{array}$ & 研究机构 & $\begin{array}{c}\text { 发文 } \\
\text { 量 }\end{array}$ & $\begin{array}{c}\text { 序 } \\
\text { 号 }\end{array}$ & 研究机构 & $\begin{array}{c}\text { 发文 } \\
\text { 量 }\end{array}$ \\
\hline 1 & 吉林大学 & 44 & 6 & $\begin{array}{c}\text { 南京农业 } \\
\text { 大学 }\end{array}$ & 20 \\
\hline 2 & 南京大学 & 40 & 7 & $\begin{array}{c}\text { 华中师范 } \\
\text { 大学 }\end{array}$ & 19 \\
\hline 3 & $\begin{array}{c}\text { 无锡职业 } \\
\text { 技术学院 }\end{array}$ & 39 & 8 & 常州大学 & 17 \\
\hline 4 & $\begin{array}{c}\text { 中国人民 } \\
\text { 大学 }\end{array}$ & 36 & 9 & $\begin{array}{c}\text { 西北农林 } \\
\text { 科技大学 }\end{array}$ & 16 \\
\hline 5 & 东华大学 & 24 & 10 & $\begin{array}{c}\text { 中国社会 } \\
\text { 科学院 }\end{array}$ & 16 \\
\hline
\end{tabular}

\section{3 研究热点分析}

关键词是论文研究主题的高度凝练和概括, 通过 在文献信息中提取能够表达文献核心内容的关键词 进行词频分析, 可以反映该领域的研究热点和发展动 向。将 Selection Criteria 赋值为“Top $\mathrm{N}=50$ ”, “ $\mathrm{TopN} \%$ $=10$ ”, 运行后得到一个包括 575 个节点、1222 条连 线、密度值为 0.0074 的关键词共现网络知识图谱。其 中, 575 个关键词中出现频次最高的 10 个关键词如 表3。

\section{表 3: 新生代农民工研究的高频关键词及首现年份} （前 10 位）

\begin{tabular}{|c|c|c|c|}
\hline 序号 & 关键词 & 出现频次 & 首现年份 \\
\hline 1 & 新生代农民工 & 1766 & 2005 \\
\hline 2 & 市民化 & 143 & 2006 \\
\hline 3 & 农民工 & 135 & 2006 \\
\hline 4 & 城市融入 & 83 & 2009 \\
\hline 5 & 影响因素 & 76 & 2007 \\
\hline 6 & 人力资本 & 50 & 2010 \\
\hline 7 & 社会资本 & 49 & 2011 \\
\hline 8 & 职业教育 & 45 & 2010 \\
\hline 9 & 城镇化 & 44 & 2010 \\
\hline 10 & 对策 & 44 & 2008 \\
\hline
\end{tabular}

如表 3 所示, “新生代农民工”的词频最高, 共计 出现 1766 次, 首现年份为 2005 年, 出自中南民族大 学成艾华教授《农民工的代际差异分析》一文。学者 们紧紧围绕“新生代农民工”研究主题, 对新老两代农 民工的代际差异、新生代农民工的市民化、城镇化、 职业教育、人力资源开发以及应对新生代农民工面临
的各种现实问题的对策措施等相关问题展开了研究， 并积聚形成了研究热点。

\section{4. 我国新生代农民工研究的前沿演进和研究 主线}

研究前沿是科学研究中最具发展潜力的研究主 题或研究领域, 揭示了今后进行特定领域研究的热点、 难点与趋势。利用 Citespace 的 Burst Detection 功能进 行关键词的突发词探测, 可以科学揭示新生代农民工 研究的前沿演进与发展趋势。根据突发词探测的结果, 结合具体的文献研究, 大致可以将 21 世纪我国新生 代农民工研究的演进历程分为 2005-2009 年、20102012 年、2013-至今等三个主要研究阶段:

第一阶段（2005-2009 年): 随着“80 后”农民工数 量逐步增多, 农民工群体内部出现了代际更替, 学者 们通过对两代农民工的代际差异、价值观变迁、发展 意愿等进行比较研究, 开启了新生代农民工研究的起 点。新生代农民工在流动动因、受教育程度、行业结 构等方面呈现出了较大的代际差异 ${ }^{[3]}$, 在消费观念上 更加开放 ${ }^{[4]}$ 、生活方式和价值观念也发生了迁移 ${ }^{\left[{ }^{[}\right]}$, 他们更倾向于将赴城务工视为人力资本和社会资本 积累的过程, 并借此谋求非农职业转化 ${ }^{[6]}$ 。有关“城市 化”问题是这一阶段的重要内容, 新生代农民工处于 一种“半城市化”状态, 在农村和城市都找不到归属 ${ }^{[7]}$, 他们在城市工作适应、人际适应上处于中等水平，但 在生活适应上却处于较低水平 ${ }^{[8]}$ 。新生代农民工的城 市化过程受到个体因素、经济因素、社会因素、制度 因素等多重困境的羁绊, 除了个体的努力之外, 也更 加呼唤政府承担起主动、积极的责任 ${ }^{[9]}$ 和社会的接纳 与支持。

第二阶段 (2010-2012 年): 2010 年中央一号文件 首次使用“新生代农民工”一词, 并明确提出要“采取 有针对性的措施, 着力解决新生代农民工问题”, 新生 代农民工受到了学界的广泛关注, 相关研究文献进入 快速增长时期。研究表明, 有关新生代农民工的特征、 现状、需求、就业、对策等主题是这一阶段的研究热 点。学者们对新生代农民工的特征进行了更为系统地 研究, 认为新生代农民工在成长环境、个人特征、就 业情况、与家乡的联系、城市适应性、流动模式、社 会团体参与率、学习倾向、外出动因、权利意识等方 面呈现出来的特征与第一代农民工存在多方面甚至 是全方位的差异 ${ }^{[10]}$, 通过对新生代农民工的居住、城 市化、就业、创业、工作满意度以及犯罪状况等多方 位问题进行研究，结合新生代农民工的信息和培训需 求、政治权利诉求等，提出了对策建议。新生代农民 工面临着被城市和农村双重边缘化、工资水平普遍偏 低且增长缓慢、社会保障体系缺位、市民化待遇缺失、 融入城市困难、心理失衡等多重困境，需要从深化户 籍制度改革、构建城乡平等就业制度、健全社会保障 体系、推进基本公共服务均等化、强化职业培训和培 育职业农业工人等多方面途径寻求破解 ${ }^{[11]}$ 。 
第三阶段（2013-至今)：在这一阶段，新生代农 民工的突出问题逐步得到解决或缓解，所引发的关注 度有所降低, 相关研究文献数量出现回落并趋于稳定。 在经历了对新生代农民工的消费行为、市民化意愿、 继续教育等问题的热切关注后, 新型城镇化、就业质 量、市民转化、赋权、身份认同、乡村振兴等相关主 题, 已然演变成为当前新生代农民工研究的前沿问题 和研究热点。研究表明, 新生代农民工的消费行为呈 现出以生存型消费为主, 并逐步向享受型与发展型消 费转变 ${ }^{[12]}$, 与城镇户籍同龄人相比, 新生代农民工在 消费结构上表现出了明显的市民化特征, 但在消费倾 向、消费水平上偏低, 经济反哺压力更大 ${ }^{[13]}$, 从而抑 制了新生代农民工的消费需求和国民内需的扩大。新 生代农民工与其父辈农民工一样, 容易在城市化中被 边缘化 ${ }^{[14]}$, 但新生代农民工的市民化意愿由于涉及到 土地承包权等方面的考量, 市民化成本较高, 新生代 农民工市民化意愿的不确定性显著提高, 在定居意愿 上呈现“二重转变”的突出特征 ${ }^{[15]}$ 。为此, 应加强职业 技能和继续教育, 提高新生代农民工的就业能力、就 业质量, 不断完善新生代农民工的就业创业、子女教 育、社会保障等制度体系 ${ }^{[16]}$, 大力推进以人为本的新 型城镇化, 着力提升城市接纳新生代农民工社会融入 的水平和质量 ${ }^{[17]}$, 促进新生代农民工的身份认同和社 会融入感。从现实情况来看, 当前新生代农民工的就 业质量、工作满意度和社会认同状况仍然较低 ${ }^{[18]}$, 在 身份认同、政治认同、文化认同、社交认同等方面均 面临困境 ${ }^{[19]}$ 。尽管所处生活和社会环境不同于第一代 农民工, 但新生代农民工传统乡土社会网络的变化不 大, 社会地位也仍处于城市社会的社会排斥之外 ${ }^{[20]}$, 需要相关部门以社会融入为指导思想提升新生代农 民工的就业质量 ${ }^{[21]}$, 采取有效措施进一步加快新生代 农民工的市民化进程与市民身份认同的“同步性”发

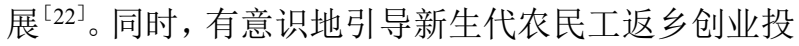
入乡村振兴, 推进城乡公共服务均等化和新型城镇化 建设, 促进城乡融合发展亦是当前新生代农民工研究 的一条重要主线。

\section{5. 结论与建议}

本文通过对 2005-2021 年间关于新生代农民工研 究的 2042 篇核心期刊、CSSCI 研究文献进行文献计 量分析, 主要得出以下结论及相关建议:

一是要进一步加强新生代农民工研究的合作研 究和跨学科研究。自 2005 年首现“新生代农民工”关 键词后, 关于新生代农民工的相关研究逐步兴起, 在 2010 年中央一号文件正式使用“新生代农民工”一词 后, 新生代农民工相关问题引起了学者们的广泛注意, 关于新生代农民工研究的相关文献迅速增加。然而, 当前新生代农民工研究领域尚未形成稳定的核心作 者群体, 发文作者之间的研究合作十分欠缺。新生代 农民工群体是随着我国社会经济发展、农民工代际更 替而产生的一个复杂的、庞大的特殊群体, 解决和治 理新生代农民工群体面临的现实问题也是一个复杂 的综合性、系统性工程, 涉及社会学、政治学、经济
学、管理学、统计学、法学、教育学、传播学等多门 类学科知识, 因此, 今后应更加注重对新生代农民工 研究的持续性和系统性, 进一步加强跨学科交流与研 究合作。

二是要进一步加强相关研究机构之间的研究合 作和学术交流, 坚持问题导向, 更加注重将理论研究 成果转化为现实的物质力量。研究发现, 新生代农民 工研究的主要研究力量集中在北京、上海、南京、武 汉等学术实力雄厚的“双一流”高校, 江苏省相关高校 在新生代农民工研究领域有着突出表现。高校是新生 代农民工研究的主要阵地, 且相关研究机构之间的研 究合作十分缺乏。为此, 今后应进一步加强不同研究 机构之间的研究合作与学术交流, 尤其有必要加强理 论研究机构与新生代农民工相关的实际工作部门的 交流和联系。新生代农民工群体是由一个个活生生的 “现实的人”组成的特殊群体，新生代农民工群体面临 的问题也是活生生的现实的社会问题, 其所具有的鲜 明问题导向决定了今后必须更加注重理论研究与具 体实践相统一，必须“把论文写在祖国的大地上”。

三是要结合新时代新生代农民工面临的实际问 题, 积极把握新生代农民工研究的热点问题、前沿问 题和研究主线, 坚持习近平总书记以人民为中心的发 展思想为指导, 强化马克思主义理论学科对新生代农 民工研究领域的理论支撑和实践指导, 推进取得更多 具有中国特色哲学社会科学的理论研究成果和开辟 具有中国特色社会主义特色的新生代农民工问题治 理之道。纵观 21 世纪我国新生代农民工研究的演进 历程和研究主线, 从以往的简单地关注“就业”演化为 强调“就业质量”、从单向的“城市融入”演变为更加注 重人们互动的“社会网络”、从相对表面的“市民化”演 变为更深层次的“身份认同”、从单纯的“城镇化”演变 为以人为本的“新型城镇化”和更加强调城市反哺乡 村的“乡村振兴”等, 不仅在一定程度上揭示了新生代 农民工研究领域的演进历程和前沿趋势, 也反映出了 中国社会的发展和进步, 反映出了新生代农民工对新 时代美好生活的向往与追求。

\section{REFERENCES}

[1] Li J., Chen C.M., (2017) Technology text mining and visualization. Capital University of Economics and Business Publishing, Beijing.

[2] Hu C.Y., Li B.L., Liao X.L., (2017) Research Hot Spot and Frontier Trend on Chinese Regional Coordinated Development Policy_-Analysis of Visual Mapping Knowledge Domain Based on CiteSpace. Journal of south China normal university(social science editiong).,5:98-109.

[3] Chen A.H., Yao S.H., (2005) Analysis of Generational Differences of Migrant Workers. J. Statistics and Decision.,20:63-65. 
[4] Wu Y., (2009) A reseach on the Characteristics of the new generation of migrant workers. J. Dong Yue tribune.,30:57-59.

[5] He J.X., Fu H.F.,(2006) Changes in the Values of the New Generation of Migrant Workers. J. Chinese Youth Studies.,4:9-12.

[6] Yue Z.S., Li S.Z., Marcus W.F., Du H.F., (2009) Wandering at Crossroad :A Comparative Study on Development Will of Two Generations of Migrant Rural Workers. J. Population \& Economics.,6:58-66.

[7] Yang X., (2008) Research on the "Semi-Urbanization" of the New Generation of Migrant Workers. J. Contemporary Youth Research.,9:6-10.

[8] Xu C.X., (2007) Falling to the Ground, but Taking No Roots-The Urban Adaptability of the Peasantworkers of the New Generation. J.South China population.,22:52-59.

[9] Li W.D., (2009) The Study of Adaptation of New Generation Migrant Workers. J. Beijing Social Sciences., 4:29-33.

[10] Liu C.J., (2010) Chinese New Generation of Migrant Workers: Characteristics, Challenges and Citizenization. J. Population research., 34:34-39.

[11] Yang C.H.(2010) Thoughts on the Problem of the New Generation of Migrant Workers. J. Agricultural economic issues., 31:80-84.

[12] Wang D., Liu Y.H., Li G., (2015) An Empirical Study on the New Peasant-workers' Consumer Behavior: Taking Lanzhou for Example. J. Northwest population., 36:117-122.

[13] Zhao W.H., (2015) An Analysis of Consumption Pattern of the New Generation of Migrant Workers. J. Beijing Social Sciences., 3:39-46.

[14] Feng C.C., (2021) Social Exclusion and Self Identification: A Study on the Urban Survival Dilemma of the New Generation of Migrant Workers. J. Social Development Research., 8:162186.

[15] Liang S.K., (2019) Dual Transformation: The Settlement Intention of the New Generation of Migrant Workers and Its Policy ImplicationsBased on the Empirical Retest of the Theory of Push and Pull. J. Henan Social Sciences., 27:107-118.

[16] Li D.S.,Yu H., Zhang L., (2019) A Study on the Intergenerational Influence of the New Generation of Migrant Workers' Willingness to MigrateBased on the dynamic monitoring data of the floating population in Sichuan Province. J. Survey the world., 10:41-47.
[17] Guo Q., (2021) The Impact of Social Integration on the Employment Quality of New-Generation Migrant Workers and Its Regional Differences. J. Economic geography.,41:161-169.

[18] Zhang M.,Zhu H.F., (2017) A research on the Employment Quality and Social Identity of the New Generation of Migrant Workers. J. Chinese Youth Studies., 1:108-112.

[19] Li K.F., (2018) The Dilemma of the New Generation of Migrant Workers' Social Identity and Its Solution. J. Agricultural economy.,5:68-69.

[20] Tang Z.Y., Zhang J.X., (2017) The social network and social integration of the new generation of migrant workers _ an analysis based on the data of the 2014 floating population dynamic monitoring survey in Jiangsu Province. J. Jiangsu Social Sciences.,5:8-15.

[21] Guo Q., (2020) Social Integration and Employment Quality of the New $R$ ural Migrant Workers. Journal of South China agricultural university(Social Science Edition) .,19:56-66.

[22] Luo S.Y., (2018) Social Network, Identity and the Psychological Crisis of the New Generation of Migrant Workers. Journal of South China agricultural university(Social Science Edition) .,17:95-105. 